\title{
Research on the Problems Existing in China's Transportation Structure and Optimization Policy
}

\author{
Shuying Chen ${ }^{1}$ \\ ${ }^{1}$ School of Economics and Management Beijing Jiaotong University Bei jing, China
}

\begin{abstract}
At present, highway transportation is the main mode of transportation in China, but highway transportation has the problem of high cost, energy consumption and pollution. Although China has put forward the development policy of public transit railway, it still needs some time to achieve this goal. This paper studies the traffic structure from the middle level; combined with empirical analysis, it is concluded that railway transport has a greater impact on national income than road transport; the existing problems and causes of China's transportation structure are analyzed and the optimization policies are put forward.
\end{abstract}

\section{Introduction}

Data from the Ministry of Transport shows that since the reform and opening up, China has witnessed rapid development in various modes of transport, and its service capacity has been greatly improved. For many years, China's total cargo throughput at ports and containers has topped the world's express business volume, vigorously supporting economic and social development. In 2017, the freight volume of the whole society reached 47.24 billion tons (of which, the freight volume of roads, waterways and railways accounted for $78 \%, 14.1 \%$ and $7.8 \%$ respectively). It can be seen that the proportion of road freight volume is greater than that of railway and waterway freight. Highway transportation has the problems of high cost, high energy consumption and high pollution. As the backbone of China's transportation system, railway has the advantages of developed road network, large traffic volume, high efficiency and environmental protection. Therefore, adjusting the transportation structure, improving the transportation efficiency and reducing the logistics cost is a major event in the structural reform of transportation supply side in recent years, it is also related to the enhancement of the competitiveness of China's real economy. This paper mainly analyzes the existing problems of China's transportation structure and puts forward the optimization policy.

\section{Literature Review}

Zhengyu Lv and Ling Ji ${ }^{[1]}$ put forward a transportation policy that considered the external cost and a comprehensive transportation system, and emphasized the importance of railway in the future. Chongjun Xiong ${ }^{[2]}$ based on DEA method, conducted an in-depth study on the coordinated development degree among China's comprehensive transportation subsystems, and analyzed the coordinated development degree among China's four modes of transportation, namely railway, highway, water transportation and civil aviation. Tianyuan Ying ${ }^{[3]}$ used the grey rate correlation analysis model to analyze and evaluate the four main modes of transportation from the statistical data of various modes of transportation, and revealed the potential linkage effect between them. Weiping Wu and Dong Wang ${ }^{[4]}$ believed that the key to the coordinated development of China's transportation system was to accelerate the development of railways, which were the backbone of China's transportation system. In addition, other studies mainly started from the technical characteristics of each mode of transportation, introduced economic resources, environment and other limiting factors, and discussed the practice mode of coordinated development of each mode of transportation.

\section{The Meaning of Transportation Structure}

According to different angles of investigation, the meaning of transportation structure is divided into three levels of macroscopic, mesoscale and microscopic, which are interrelated and permeated each other. Macro level from the national economy as a whole to investigate the transport capacity of transport and transport needs of the degree of adaptation. The middle level examines the composition of various modes of transport from within the transport industry, that is, the volume distribution and composition ratio among the five modes of transport. This paper is mainly from the middle level analysis, when the five modes of transportation reach the appropriate proportion, the traffic structure will reach the optimal. 


\section{Empirical Analysis}

\subsection{Datas Sources}

The selected datas are from China Statistical Yearbook.

\subsection{Index for Selection}

In order to analyze the impact of road transport and railway transport on national income, the following indicators are selected for empirical analysis. Through multiple linear regression analysis, the influence degree of road transport and railway transport on national income is obtained. Y: Gross national income (100 million yuan); $A_{11}$ : Railway operating mileage $(\mathrm{km}) ; A_{12}$ : Highway mileage $(\mathrm{km}) ; B_{11}$ : Railway passenger volume (10000 people); $B_{12}$ : Highway passenger traffic volume (10000 people); $C_{11}$ : Railway freight volume (10000 tons); $C_{12}$ : Road freight volume (10000 tons); $D_{11}$ : Railway passenger turnover (100 million person kilometers); $D_{12}$ : Highway passenger turnover (100 million person kilometers); $E_{11}$ : Railway freight turnover (100 million ton $\mathrm{km}) ; E_{12}$ : Highway freight turnover (100 million ton $\mathrm{km})$.

\subsection{Multiple Linear Regression Analysis}

\subsubsection{The General Form of Multiple Linear Regression Model is Established:

$$
Y=\beta_{0}+\beta_{1} A_{11}+\beta_{2} B_{11}+\beta_{3} C_{11}+\beta_{4} D_{11}+\beta_{5} E_{11}
$$$$
Y=\beta_{0}^{\prime}+\beta_{1}^{\prime} A_{12}+\beta_{2}^{\prime} B_{12}+\beta_{3}^{\prime} C_{12}+\beta_{4}^{\prime} D_{12}+\beta_{5}^{\prime} E_{12}
$$

\subsubsection{The Establishment of Multiple Linear Regression Model}

Table1. Multivariate regression estimates of national income and railway transport indicators (1)

\begin{tabular}{|c|r|r|r|r|}
\hline Variable & Coefficient & \multicolumn{1}{l|}{ Std. Error } & \multicolumn{1}{c|}{ t-Statistic } & \multicolumn{1}{l|}{ Prob. } \\
\hline C & -753901.6 & 326807.8 & -2.306865 & 0.0823 \\
\hline$A_{11}$ & 6.982638 & 5.655650 & 1.234630 & 0.2845 \\
\hline$B_{11}$ & 0.486957 & 0.719208 & 0.677073 & 0.5355 \\
\hline$C_{11}$ & -0.189477 & 1.758505 & -0.107749 & 0.9194 \\
\hline$D_{11}$ & 17.63325 & 47.70215 & 0.369653 & 0.7304 \\
\hline$E_{11}$ & 13.79303 & 23.99834 & 0.574749 & 0.5962 \\
\hline R-squared & 0.996581 & Mean dependent var & 616763.9 \\
\hline Adjusted R-squared & 0.992306 & S.D. dependent var & 176729.0 \\
\hline S.E. of regression & 15501.54 & Akaike info criterion & 22.41898 \\
\hline Sum squared resid & $9.61 \mathrm{E}+08$ & Schwarz criterion & 22.60053 \\
\hline Log likelihood & -106.0949 & Hannan-Quinn criter. & 22.21981 \\
\hline F-statistic & 233.1585 & Durbin-Watson stat & 2.043418 \\
\hline Prob(F-statistic) & 0.000051 & & \\
\hline
\end{tabular}

The estimation results of Eviews software are shown in Table $1, R^{2}=0.996581, \mathrm{P}=0.000051$, and the equation integrity is significant, but the $\mathrm{P}$ values of $A_{11}, B_{11}, C_{11}$, $D_{11}, E_{11}$ are all greater than 0.1 , and fail to pass the test. The coefficient of $C_{11}$ is negative, which is obviously unreasonable, which indicates that there may be collinearity between independent variables. Therefore, the multicollinearity test is carried out next.

Table2. Correlation coefficient of independent variables

\begin{tabular}{|c|c|c|c|c|c|}
\hline & $A_{11}$ & $B_{11}$ & $C_{11}$ & $D_{11}$ & $E_{11}$ \\
\hline$A_{11}$ & 1.000000 & 0.980366 & -0.000744 & 0.986610 & -0.276654 \\
\hline$B_{11}$ & 0.980366 & 1.000000 & 0.105715 & 0.989205 & -0.156253 \\
\hline$C_{11}$ & -0.000744 & 0.105715 & 1.000000 & 0.149219 & 0.952588 \\
\hline$D_{11}$ & 0.986610 & 0.989205 & 0.149219 & 1.000000 & -0.126688 \\
\hline$E_{11}$ & -0.276654 & -0.156253 & 0.952588 & -0.126688 & 1.000000 \\
\hline \multicolumn{2}{|r}{ It can be seen from table 2 that the correlation }
\end{tabular}
coefficient of $A_{11}$ and $B_{11}$ is 0.980366 ; the correlation coefficient of $C_{11}$ and $E_{11}$ is 0.952588 ; the correlation coefficient of $A_{11}$ and $D_{11}$ is 0.986610 , indicating that there is a multicollinearity problem.

Table3. Multivariate regression estimates of national income and railway transport indicators (2)

\begin{tabular}{|c|c|c|c|c|}
\hline Variable & Coefficient & Std. Error & t-Statistic & Prob. \\
\hline C & -1001827. & 74022.10 & -13.53417 & 0.0000 \\
\hline$A_{11}$ & 10.98140 & 0.286273 & 38.35991 & 0.0000 \\
\hline$E_{11}$ & 15.68210 & 2.171908 & 7.220426 & 0.0002 \\
\hline R-squared & 0.995305 & Mean dependent var & 616763.9 \\
\hline Adjusted R-squared & 0.993964 & S.D. dependent var & 176729.0 \\
\hline S.E. of regression & 13730.89 & Akaike info criterion & 22.13601 \\
\hline Sum squared resid & $1.32 \mathrm{E}+09$ & Schwarz criterion & 22.22678 \\
\hline Log likelihood & -107.6800 & Hannan-Quinn criter. & 22.03643 \\
\hline F-statistic & 741.9709 & Durbin-Watson stat & 2.110270 \\
\hline Prob(F-statistic) & 0.000000 & & & \\
\hline The estimation & & \\
\hline
\end{tabular}

The estimation results of Eviews software are shown in Table $3, R^{2}=0.995305, \mathrm{P}=0.000000$, and the equation integrity is significant. The $\mathrm{P}$ values of the constant term, $A_{11}, E_{11}$ are all less than 0.05 , which have passed the test. So the following regression equation can be obtained:

$$
Y=-1001827+10.98140 A_{11}+15.68210 E_{11}
$$

Table4. Multivariate regression estimates of national income and road transport indicators (1)

\begin{tabular}{|c|r|r|r|r|}
\hline Variable & Coefficient & \multicolumn{1}{c|}{ Std. Error } & \multicolumn{1}{c|}{ t-Statistic } & \multicolumn{1}{l|}{ Prob. } \\
\hline $\mathbf{C}$ & -1241231 & 454601.3 & -2.730373 & 0.0524 \\
\hline$A_{12}$ & 0.368874 & 0.098630 & 3.739973 & 0.0201 \\
\hline$B_{12}$ & 0.137209 & 0.136824 & 1.002811 & 0.3727 \\
\hline$C_{12}$ & 0.121297 & 0.412582 & 0.293994 & 0.7834 \\
\hline$D_{12}$ & -35.81068 & 39.09910 & -0.915895 & 0.4115 \\
\hline$E_{12}$ & 0.134636 & 24.61137 & 0.005470 & 0.9959 \\
\hline R-squared & 0.997892 & Mean dependent var & 616763.9 \\
\hline Adjusted R-squared & 0.995257 & S.D. dependent var & 176729.0 \\
\hline S.E. of regression & 12171.18 & Akaike info criterion & 21.93524 \\
\hline Sum squared resid & $5.93 \mathrm{E}+08$ & Schwarz criterion & 22.11679 \\
\hline Log likelihood & -103.6762 & Hannan-Quinn criter. & 21.73608 \\
\hline F-statistic & 378.7099 & Durbin-Watson stat & 2.907791 \\
\hline Prob(F-statistic) & 0.000019 & & & \\
\hline
\end{tabular}

The estimation results of Eviews software are shown in Table 4. The resolvable coefficient $R^{2}=0.997892, \mathrm{P}=0$. 000019. The equation is of significant integrity. However, the $\mathrm{P}$ values of $B_{12}, C_{12}, D_{12}$ and $E_{12}$ are all greater 
than 0.1 , which fails to pass the test. Moreover, in this regression equation, the coefficient of $D_{12}$ is negative, which is obviously unreasonable. This indicates that there may be collinearity between independent variables. Therefore, after the multicollinearity test, the multiple linear relationship is shown in the table 5:

Table5. Multivariate regression estimates of national income and road transport indicators (2)

\begin{tabular}{|c|r|r|r|r|}
\hline Variable & Coefficient & Std. Error & t-Statistic & Prob. \\
\hline C & -1411800 & 155221.7 & -9.095382 & 0.0000 \\
\hline$A_{12}$ & 0.410064 & 0.058361 & 7.026400 & 0.0002 \\
\hline$C_{12}$ & 0.073016 & 0.036222 & 2.015780 & 0.0836 \\
\hline R-squared & 0.990030 & Mean dependent var & 616763.9 \\
\hline Adjusted R-squared & 0.987181 & S.D. dependent var & 176729.0 \\
\hline S.E. of regression & 20009.26 & Akaike info criterion & 22.88910 \\
\hline Sum squared resid & $2.80 \mathrm{E}+09$ & Schwarz criterion & 22.97988 \\
\hline Log likelihood & -111.4455 & Hannan-Quinn criter. & 22.78952 \\
\hline F-statistic & 347.5477 & Durbin-Watson stat & 0.983672 \\
\hline Prob(F-statistic) & 0.000000 & & & \\
\hline The estimation & & & \\
\hline
\end{tabular}

The estimation results of Eviews software are shown in Table $5, R^{2}=0.995305, \mathrm{P}=0.000000$, and the equation integrity is significant. The $\mathrm{P}$ values of the constant term, $A_{12}, C_{12}$ are all less than 0.05 , which have passed the test. So the following regression equation can be obtained:

$$
Y=-1411800+0.410064 A_{12}+0.073016 C_{12}
$$

\subsection{Conclusion}

Through the multiple regression estimation of national income and various indexes of railway transportation and highway transportation, it can be concluded that the influence coefficients of railway operating mileage, railway cargo turnover, highway mileage and highway freight volume on national income are 10.98140,15.68210,0.410064 and 0.073016, respectively. Therefore, compared with road transport, railway transport has a greater influence on national income, and its influence is more significant. China should increase the railway operating mileage, increase the railway cargo transport, and increase the implementation of the policy of circular railway.

\section{Problems and Causes of Transportation Structure in China}

\subsection{Mainly by Highway, Railway Supply Is Insufficient}

Most of modern transportation is based on road transportation, which can accomplish the alternation of goods in the shortest time. However, there are some problems such as overloading and environmental pollution in road transportation. In 2018, the length of China's transport highway line is about 37 times that of railway line, and the proportion of railway investment in GDP is small, showing a downward trend in recent years. The reason is the lack of government financial direct investment in railway infrastructure construction. Although some central and local governments have launched joint ventures to build roads, allowing private capital to enter the field of railway infrastructure, in general, local and private capital invests little in railway construction and the supply of railway is insufficient.

\subsection{The Layout of Transportation Facilities Is Not Conducive to The Coordinated Development Between Regions}

In recent years, China has increased the investment in the construction of transportation facilities in the central and western regions, and the construction of transportation infrastructure in the western region has been strengthened. However, compared with the eastern coastal areas, the distribution of transportation network in the western region is unbalanced and the backward transportation facilities are still prominent ${ }^{[5]}$. The layout of China's transportation facilities is that the east is superior to the west, and the highway and railway facilities are mainly concentrated in the east. The development of transportation facilities plays an important role in promoting regional economic development. Generally speaking, the gap between the western region and the eastern region is widening due to the low level of highway technology, poor driving conditions and fewer railway lines, which is one of the important factors restricting the economic development of the central and western regions.

\subsection{Multimodal Transport Is Developing Slowly}

The development of multimodal transport and "door-todoor" transport has been widely used in developed countries and has brought great economic benefits. However, the development in China is very slow and is still in the primary stage. Although road transport has problems such as high pollution and high cost, it is difficult to provide "door-to-door" service due to the limited use of standard containers in China's railway transport, with problems in the first and last kilometer. It is beneficial to the development of multimodal transport to make the railway transport connect seamlessly with other modes of transport and improve the convenience of railway transport ${ }^{[6]}$.

\subsection{Flexibility in Tariff Setting Varies Greatly}

Road transport is in a perfectly competitive market with high flexibility of freight rate. Therefore, in order to gain more profits, truck drivers will slightly reduce the price and increase the load. In addition, road transport still has the situation of backhaul delivery. However, railway transportation is in a monopolized market, controlled by the state, with less flexibility in freight rate and no bargaining power. Therefore, customers choose road transportation in order to save costs. In order to increase the quantity of railway transportation, the state should relax the control of railway freight rate, join the private investment, form the competitive market of railway transportation, increase people's choice of railway 
transportation, and facilitate the continuous innovation of railway freight transportation enterprises in the competition.

\section{Conclusion}

The empirical analysis shows that railway transport has a more significant impact on national income than road transport. Based on the existing problems in China's transport structure, the following four optimization policies are proposed.

\subsection{Optimize The Transport Supply Structure}

On the basis of ensuring that the transport supply can meet the demand for transport, it should be kept ahead of time, mainly because the increase of transport supply has a construction cycle, while the transport demand is a continuous growth process. The optimization of supply structure will directly affect people's choice of transportation mode, so the government needs to strengthen the planning of infrastructure construction, especially the network connection of transportation mode and the planning of comprehensive hub.

\subsection{Implementing The Mode of Coordinated Development of Railway Priority and Other Modes of Transportation}

Each transport mode there are their respective advantages and disadvantages, but if geographical environment and economic conditions allow, first of all should is in the development of railway transportation, this is mainly because the railway can realize long-distance transportation, can in the shortest possible time to achieve the most a lot of people and goods transfer, and relative to the highway transportation is more environmental protection $^{[7]}$. China's transportation structure should establish the position of railway as far as possible and develop in harmony with other modes of transportation, not only from the railway's own characteristics, but also because the railway can solve the problem of China's vast territory and uneven distribution of resources to a great extent, and has an extremely important strategic position and role.

\subsection{Create a Fair and Reasonable Competitive Environment}

In addition to the reasonable control of road transport, China's transport structural adjustment policy should strengthen the market competitiveness of railway transport. At present, the railway is mainly in a monopoly position, and the state has absolute control. The state can appropriately relax the control of the railway, introduce private investment, form the railway freight price competition, and promote the continuous innovation of railway freight enterprises in the competition.

\subsection{Improve and Standardize Transportation Management}

We will strengthen management of transportation in the transportation sector and, through policy guidance, enable various modes of transportation to give full play to their respective advantages, so that medium and long-distance freight transport will be shifted to railways. At present, one of the prominent problems facing is the truck overload engaged in long distance transport, which not only can not give play to its distance advantage, but also bring serious hidden trouble to road safety ${ }^{[8]}$. Therefore, the relevant departments need to take measures to realize the long distance transport of overloaded highway freight transport to railway transport, which can effectively improve the railway freight share rate. Improving and standardizing transportation management can effectively transfer unreasonable freight from highway to railway.

\section{Acknowledgements}

I would like to thank my teacher for her guidance. His rigorous, earnest and hardworking attitude towards academic research is worthy of my lifelong learning. Meanwhile, I would also like to thank my teacher for giving me the greatest help when I was confused. Thank you for classmates' advice and help during my study. Thank you for your tolerance in life. Finally, I would like to thank my family, thank you for your constant support, thank you for your selfless company and help, you are my strongest backing.

\section{References}

1. Zhengyu Lv and Ling Ji, "Transportation cost analysis considering energy security and external cost,"Journal of Transportation Engineering and Information, vol.1, pp. 92-98, 2004.

2. Chongjun Xiong, Yixi Ning and Yingli Pan, "Evaluation and Research on coordinated Development of China's comprehensive transportation modes," Systems Engineering, vol.6, pp. 1-7, 2006.

3. Tianyuan Ying, "The correlation analysis and evaluation of main transportation modes in China and its enlightenment," Shipping Management, vol.03, pp. 26-29. 1997.

4. Weiping $\mathrm{Wu}$ and Dong Wang, "Research on the Coordinated Development of Various transportation modes in China," Railway Economics Research, vol.2, pp. 29-33, 2005.

5. Dongsheng Xiao, "Analysis of the causes of problems in China's comprehensive transport structure," Comprehensive Transportation, vol. 9, pp. 8-11, 2003.

6. Shuling Chen, Zhaoxia Kang, and Jianhong $\mathrm{Wu}$, "International comparison and enlightenment of transportation structural Adjustment policies,"Railway Transport and Economy, vol. 02, pp. 33-37, 2018. 
7. Wenhui $\mathrm{Xi}$ and Shengwen Yang, "Analysis and adjustment strategy of China's transportation structure," Jiangsu Science and Technology Information, vol.08, pp. 21-23, 2019.

8. Xinjun Zhou, "Transformation and Development of Railway Freight transport in China: From the perspective of optimization of comprehensive transportation structure," Journal of North China Electric Power University (Social Science edition), vol. 02, pp. 48-61, 2009. 